\title{
A Rare Case of Primary Mucinous Cystadenoma of Spleen
}

\author{
Onkar Singh ${ }^{\mathrm{a}, \mathrm{b}}$, Shilpi Gupta ${ }^{\mathrm{a}}$, Sumit Shukla ${ }^{\mathrm{a}}$, Raj Kumar Mathur ${ }^{\mathrm{a}}$
}

\begin{abstract}
Mucinous cystadenomas are relatively uncommon benign cystic tumors. Most of them are found in the ovary, pancreas, and appendix. Primary mucinous cystadenoma of spleen is extremely rare and only countable cases have been recorded. These are assumed to arise from heterotopic pancreatic tissue or invaginated spleenic capsular mesothelium. We present a rare case of primary mucinous cystadenoma of spleen without pancreatic tissue in it. Exact tissue of origin could not be determined.
\end{abstract}

Keywords: Cystadenoma; Splenic cyst; Pseudomyxoma peritonei

\section{Introduction}

Mucinous cystadenomas are relatively uncommon benign cystic tumors. Most of them are found in the ovary, pancreas, and appendix. However, they have also been identified in other unusual sites such as retroperitoneum, fallopian tube, lung, urinary bladder, and liver. Primary mucinous cystadenoma of spleen has been reported very rarely. In these cases it was presumed that the tumor arose either from invaginated capsular mesothelium of the spleen or from heterotopic pancreatic $[1,2]$ or enteric tissue within the spleen $[3,4]$. We report an extremely rare case of primary mucinous cystadenoma of spleen. Only few cases have been documented in the literature [3-7].

\section{Case Report}

A 22-year-old male presented with dull aching pain as-

\footnotetext{
Manuscript accepted for publication June 28, 2009

${ }^{a}$ Department of surgery, MGM Medical College \& MY Hospital Indore, 452001, India

${ }^{b}$ Corresponding author, email: dronkarsingh@gmail.com
}

doi:10.4021/jocmr2009.09.1257 sociated with a slow growing lump in left hypochondrium for 3 months. Physical examination revealed a well-defined ovoid, nontender, non pulsatile, smooth surfaced mass of size approximately $24 \times 16 \mathrm{~cm}$, that involved the left hypochondrium, epigastrium and umbilical regions, and was moving with respiration. Ultrasonography (USG) abdomen suggested inferiorly displaced spleen due to a large welldefined hypoechoic cystic mass of size $15 \times 10 \mathrm{~cm}$. Barium meal examination showed extra luminal indentation of left lateral wall of stomach. Passage of barium through stomach and duodenum was smooth. Magnetic resonance imaging (MRI) demonstrated a large well-defined, unilocular, cystic, encapsulated lesion of size $20.2 \times 19.3 \times 15.1 \mathrm{~cm}$ in left subdiaphgramatic region, arising form spleen, with hyper intense signal on both $\mathrm{T} 1$ and $\mathrm{T} 2$, producing marked compression and displacement of adjacent structures (Fig. 1). Pancreas, appendix and liver were normal.

On exploratory laparotomy, a tense and cystic mass, of size $20 \times 15 \mathrm{~cm}$, arising from the diaphragmatic surface of spleen, involving the whole left hypochondrium with extension into the umbilical region and epigastric region displacing the stomach to right side, was found. Other common sites for cystic lesion like pancreas, appendix, mesentery, and liver were found normal. Splenectomy was done. The cut surface showed unilocular cystic mass with smooth in-

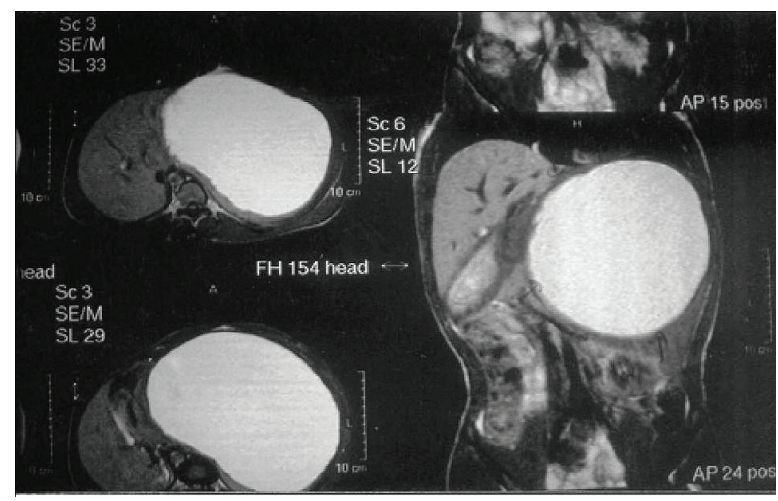

Figure 1. MRI demonstrating a large well-defined, unilocular, cystic, encapsulated lesion of spleen. 


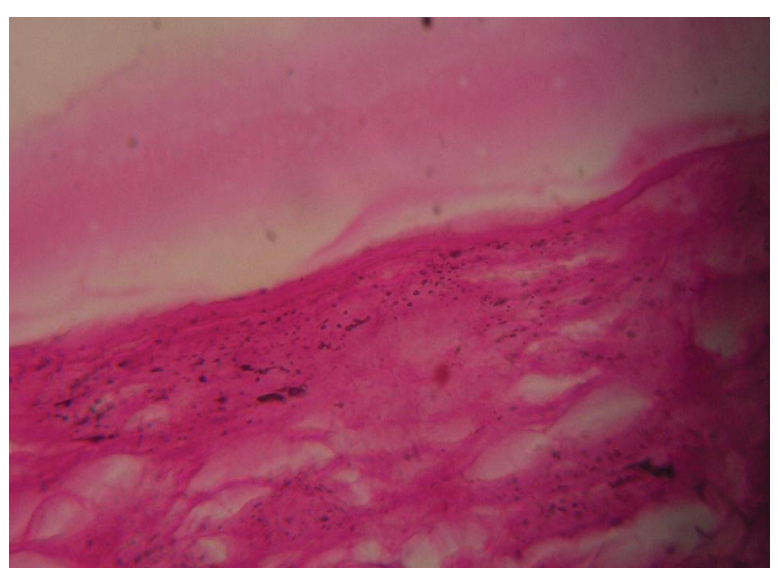

Figure 2. Histopathological examination showing unilocular mucinous cystadenoma of spleen.

ner surface and profuse insipissated mucus. Microscopically, papillary structure was found on the inner surface of cystic space, which was lined by a single layer of mucin-producing epithelial cells without malignant change. The splenic tissue was outside the cystic wall. Histopathological examination was suggestive of unilocular mucinous cystadenoma of spleen (Fig. 2). No pancreatic tissue was found in the specimen. Patient was discharged one week later. Abdominal USG demonstrated no recurrence one year later.

\section{Discussion}

Splenic tumors are uncommon neoplasms. Morgenstern et al. classified splenic tumors into four categories: lymphoid tumors, non-lymphoid tumors, metastatic tumors, and tumor-like lesions, such as cysts and hamartomas. The most common non-lymphoid tumors are vascular tumors. However, primary splenic tumors arising from epithelial origin are extremely rare [8].

Splenic mucinous cystic tumors are defined as cystic spaces lined by mucin-producing columnar cells and ranged from benign cystadenoma to frankly malignant cystadenocarcinoma. Primary mucinous cystadenoma of spleen is an extremely rare finding $[3,4,6,7]$. The exact histogenetic mechanism of splenic mucinous cystic tumors is unknown except those arising from heterotopic pancreatic tissues [1]. However, mucinous cysts are usually found in association with the cystadenoma of pancreas, pseudomyxoma peritonei and mucocele of appendix [7]. Only few cases, in which the tissue of origin was un-defined, are documented in the literature [3-7].

Simple mucinous cyst of spleen is a rare and close differential diagnosis, which may rarely present as pseudomyxoma peritonei [9]. Distinction is difficult to make because of low incidence and nonspecific imaging finding. Ultrasound and MRI scan, in case of mucinous cystadenoma may demonstrate a cystic lesion which may or may not contain an internal septum. Anyway, definitive diagnosis is made by surgical exploration and histopathology. Only few cases of primary mucinous cystadenoma of spleen have been reported in which tissue of origin was undefined although pseudomyxoma peritonei may uncommonly present as splenic metastasis [10]. In our case, pancreas was normal and there were no definite heterotopic pancreatic tissues in and around the splenic lesion. So, the exact histogenetic mechanism was not known. Going by Morinaga's presentation [3], we concluded that the primary splenic mucinous cystadenoma may originate in the invagination of the splenic capsular mesothelium.

In conclusion, a rare case of primary mucinous cystadenoma of spleen is presented. Tissue of origin may or may not be identifiable, but it is hetertopic pancreas usually or invaginated splenic capsular mesothelium.

\section{Conflict of Interest}

The author declares no conflict of interest.

\section{References}

1. Zanetti G, Riccioni L, Gallo C, Salfi N, Martinelli GN. Splenic mucinous cystadenocarcinoma arising in heterotopic pancreatic tissue. Tumori 1998;84(5):606-610.

2. Souilamas MR, Khayat M, el Arbi N, Soulier Y. [A rare case of proctorrhagia. Apropos of a case and review of the literature]. Ann Chir 1993;47(3):267-269.

3. Morinaga S, Ohyama R, Koizumi J. Low-grade mucinous cystadenocarcinoma in the spleen. Am J Surg Pathol 1992;16(9):903-908.

4. Nisar PJ, Zaitoun AM, Lobo DN, Rowlands BJ. Heterotopic pancreas in the spleen: malignant degeneration to mucinous cystadenocarcinoma. Eur J Gastroenterol Hepatol 2002;14(7):793-796.

5. Dedic N, Premuzic M, Cavka S, Ostojic R, Hrstic I, Vucelic B. [Pseudomyxoma peritonei associated with splenic mucinous epithelial cysts--case report]. Lijec Vjesn 2000;122(11-12):272-275.

6. Kapoor S, Naik S, Sharma S, Varshney S. Pseudomyxoma peritonei due to a ruptured mucinous cystadenoma of the spleen. European Surgery. 2007; 39 (5):314-316.

7. Hirota M, Hayashi N, Tomioka T, Murakami S, Ohshima H, Yamasaki K, Miyamoto J, et al. Mucinous cystadenocarcinoma of the spleen presenting a point mutation of the Kirsten-ras oncogene at codon 12. Dig Dis Sci 1999;44(4):768-774.

8. Morgenstern L, Rosenberg J, Geller SA. Tumors of the spleen. World J Surg 1985;9(3):468-476. 
9. Kruslin B. [Pseudomyxoma peritonei associated with mucinous epithelial cysts of the spleen]. Lijec Vjesn 2001;123(5-6):154.

10. Shimoyama S, Kuramoto S, Kawahara M, Yamasaki
K, Endo H, Murakami T, Kaminishi M. A rare case of pseudomyxoma peritonei presenting an unusual inguinal hernia and splenic metastasis. J Gastroenterol Hepatol 2001;16(7):825-829. 